\title{
An electromyographic study of uterotubal activity in the ewe
}

\author{
Y. Ruckebusch and L. Bueno \\ Laboratoire de Physiologie et Pharmacodynamie, Ecole Nationale Vétérinaire, \\ 31076 Toulouse, France*
}

\begin{abstract}
Summary. The electrical activity of the oviduct and uterus was automatically registered on a potentiometric pen recorder in ewes fitted with an extracellular multielectrode assembly. The duration and amplitude of local non-propagating activity of the uterus increased and became progressively grouped into phases as natural oestrus progressed. Phases of contractions lasting 5-6 min were initially propagated at a rate of $2 / \mathrm{hr}$. Their frequency increased within $24 \mathrm{hr}$ of the decline in plasma progesterone levels. Grouped activity was then resumed for the next $24 \mathrm{hr}$. Similar changes were seen in the activity of the oviduct although this region was active earlier in oestrus.

The uterotubal activity developed in the same way $24 \mathrm{hr}$ after withdrawal of a progestagen-impregnated sponge but lasted for 3 days. When another oestrus was induced by injection of a prostaglandin analogue, the activity patterns were qualitatively similar although they did not start until $36 \mathrm{hr}$ after injection and lasted for only 2 days.
\end{abstract}

\section{Introduction}

The pattern of motility of the genital tract of many species undergoes marked changes during the oestrous cycle. In the ewe, endoscopic examination of the uterus revealed rhythmic coiling and uncoiling during an oestrous period of about $72 \mathrm{hr}$ (Lehrer \& Schindler, 1974). Observations at laparotomy indicated that the direction of uterine contractions was reversed after ovulation (Hawk, 1975). Increased pressure in the lumen of the uterus at the time of oestrus has also been described (Lightfoot, 1970). Further information has recently been provided by electromyographic exploration of the uterine smooth muscle. Using electrodes sewn onto the myometrium, Naaktgeboren et al. (1973) recorded a peak of activity around the time of normal oestrus. This phenomenon was also observed in ovariectomized ewes $24-36 \mathrm{hr}$ after the injection of oestradiol benzoate (Rousseau \& Prud'homme, 1974).

These investigations were limited, however, by the size of the insulating base of the electrodes used, which was too large to permit the placing of electrodes on the oviduct. Fine wire electrodes have been successfully implanted directly in the wall of the oviduct and uterus in cattle (Ruckebusch \& Bayard, 1975), sheep (Ruckebusch \& Pichot, 1975) and rabbits (Ruckebusch, 1975).

The aim of the present work was to analyse the electrical spiking activity of the oviduct and uterus of the ewe during natural and induced oestrus.

\section{Materials and Methods}

The experiments were conducted during the breeding season on 6 parous 3-4-year-old Charmoise ewes weighing about $50 \mathrm{~kg}$. Oestrus was detected by the presence of a teaser ram, and after being fasted for 2 days the ewes were subjected to laparotomy under general anaesthesia $(20 \mathrm{mg}$ pentobarbitone sodium $/ \mathrm{kg}$ ). Electrodes were made from insulated nichrome wires $80 \mu \mathrm{m}$ in diameter and

* Postal address: Ecole Nationale Vétérinaire, 23, chemin des Capelles, F-31076, Toulouse Cédex, France. 
100-200 cm in length (Trinamel: Johnson Matthey Ltd, London), the insulation being burnt from one end before use. They were inserted through the serosa and muscular layer of the oviduct and uterus in groups of three, $2 \mathrm{~mm}$ apart, using a needle as a trocar. The free end was tied off close to the wall and the electrodes were passed to the exterior through a stab wound between the shoulders. The length of the electrode wires allowed the animals to lie down and move freely in the cage without risk of damage to the recording apparatus. Six groups of electrodes were fixed bilaterally: 2 on the ampulla, 2 on the isthmus and 2 on the uterus. Insulation and fixation were achieved by proliferation of the serosa in approximately $2-4$ days.

Animals were housed in individual pens and the electrical activity was monitored throughout the experiment by direct connection of two of the three electrodes of each group to a 12-channel polygraph ( $R C$ coupling, time constant $0.1 \mathrm{sec}$ : Reega, Alvar, Paris). For each ewe, the output of 4 channels of the polygraph was continuously plotted over 2 months using a linear integrator (Latour, 1973). Electrical activity was summed at 30 -sec intervals and values indicated via a potentiometric recorder (chart speed $2 \mathrm{~cm} / \mathrm{hr}$ ). Polygraph recordings were made daily from all 12 electrode sites for $8 \mathrm{hr}$.

Two ewes received no additional treatment. Four animals were maintained in dioestrus for 2 weeks by means of a Cronolone (SC 9880)-impregnated sponge ( $30 \mathrm{mg} 17 \alpha$-acetoxy-9 $\alpha$-fluoro-11 $\beta$ hydroxypregn-4-ene-3:20-dione: Searle, Montrouge) inserted intravaginally at surgery. Oestrus was induced 10 days later by withdrawal of the sponge and i.m. injection of 400 i.u. PMSG (Searle).

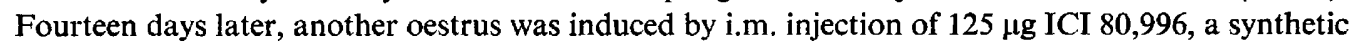
analogue of prostaglandin F-2 $\alpha$, and 400 i.u. PMSG.

Jugular blood samples were taken daily from 14 to 20 days after surgery in the control ewes, and from 2 days before to 4 days after sponge withdrawal or prostaglandin treatment. The plasma was stored at $-20^{\circ} \mathrm{C}$ and progesterone concentrations were measured by radioimmunoassay (Ruckebusch \& Bayard, 1975).

\section{Results}

\section{Progesterone levels}

In the two control ewes, plasma progesterone concentrations indicated a normal luteal function (Haresign, Foster, Haynes, Crighton \& Lamming, 1975). Levels began to rise 2 days after the end of the previous oestrus and remained elevated at about $4 \mathrm{ng} / \mathrm{ml}$ for 10-12 days. Fifteen days after the previous standing oestrus, the progesterone concentration decreased to $<1 \mathrm{ng} / \mathrm{ml}$ and remained depressed for 4 days (Table 1). Identical changes were observed during a second oestrous cycle.

Table 1. Peripheral plasma progesterone levels and uterotubal activity during natural and induced oestrus in ewes

\begin{tabular}{|c|c|c|c|c|c|c|c|}
\hline \multicolumn{8}{|l|}{ Natural oestrus } \\
\hline $\begin{array}{l}\text { Days after previous standing } \\
\text { oestrus }\end{array}$ & 14 & 15 & 16 & 17 & 18 & 19 & 20 \\
\hline Plasma progesterone* $(\mathrm{ng} / \mathrm{ml})$ & $4 \cdot 0$ & 0.7 & 0.7 & $0 \cdot 6$ & 0.6 & $1 \cdot 2$ & $3 \cdot 7$ \\
\hline Uterotubal activity & & & + & + & & & \\
\hline \multicolumn{8}{|l|}{ Induced oestrus } \\
\hline $\begin{array}{l}\text { Time relative to treatment } \\
\text { (days) }\end{array}$ & -2 & -1 & 0 & 1 & 2 & 3 & 4 \\
\hline \multicolumn{8}{|l|}{ (1) Sponge withdrawal + PMSG } \\
\hline $\begin{array}{l}\text { Plasma progesterone }(\mathrm{ng} / \mathrm{ml}) \\
\text { Uterotubal activity }\end{array}$ & $\begin{array}{l}4 \cdot 6 \\
\pm 0 \cdot 8\end{array}$ & $\begin{array}{l}4 \cdot 2 \\
\pm 0.9\end{array}$ & $\begin{array}{l}4 \cdot 0 \\
\pm 1 \cdot 1\end{array}$ & $\begin{array}{l}0.9 \\
\pm 0.4\end{array}$ & $\begin{array}{l}0.8 \\
\pm 0.7 \\
+\end{array}$ & $\begin{array}{l}0.6 \\
\pm 0.6 \\
+\end{array}$ & $\begin{array}{l}0.8 \\
\pm 0.9 \\
+\end{array}$ \\
\hline \multicolumn{8}{|c|}{ (2) Prostaglandin analogue injection + PMSG } \\
\hline $\begin{array}{l}\text { Plasma progesterone } \nmid(\mathrm{ng} / \mathrm{ml}) \\
\text { Uterotubal activity }\end{array}$ & $\begin{array}{l}3 \cdot 6 \\
\pm 0 \cdot 8\end{array}$ & $\begin{array}{l}4 \cdot 0 \\
\pm 0.6\end{array}$ & $\begin{array}{l}4 \cdot 0 \\
\pm 0 \cdot 6\end{array}$ & $\begin{array}{l}3 \cdot 2 \\
\pm 0.7\end{array}$ & $\begin{array}{l}1 \cdot 6 \\
\pm 0 \cdot 3 \\
+\end{array}$ & $\begin{array}{l}0.8 \\
\pm 0.9 \\
+\end{array}$ & $\begin{array}{l}3 \cdot 2 \\
\pm 0 \cdot 9\end{array}$ \\
\hline
\end{tabular}

+ Indicates the onset of continuous tubal activity and subsequent phases of activity of the same magnitude.

* Mean values for 2 animals.

$\dagger$ Mean values \pm S.E.M. for 4 animals. 
The progesterone concentration also decreased in the 4 treated animals, from $5 \mathrm{ng} / \mathrm{ml}$ to $<0.8$ $\mathrm{ng} / \mathrm{ml}$, within $24 \mathrm{hr}$ of sponge withdrawal. Levels remained low for the next 3 days. When the prostaglandin analogue was injected 14 days later, the progesterone level again fell, but more slowly and for a shorter time (Table 1).

\section{Patterns of electrical activity}

The electrical activity of the oviduct and uterus varied considerably during the course of natural oestrus. Isolated potentials predominated on the oviduct, whereas bursts of high-and low-amplitude potentials were recorded from the uterus. During dioestrus, until 16 days after the previous standing heat, only sporadic weak potentials were detected in the control ewes. More constant activity was exhibited by the isthmus near the uterotubal junction and every 2 to $3 \mathrm{hr}$, one of the oviducts displayed a pattern of regular small bursts of low amplitude. Similar patterns were observed during the 10 days of induced dioestrus (Text-fig. 1).

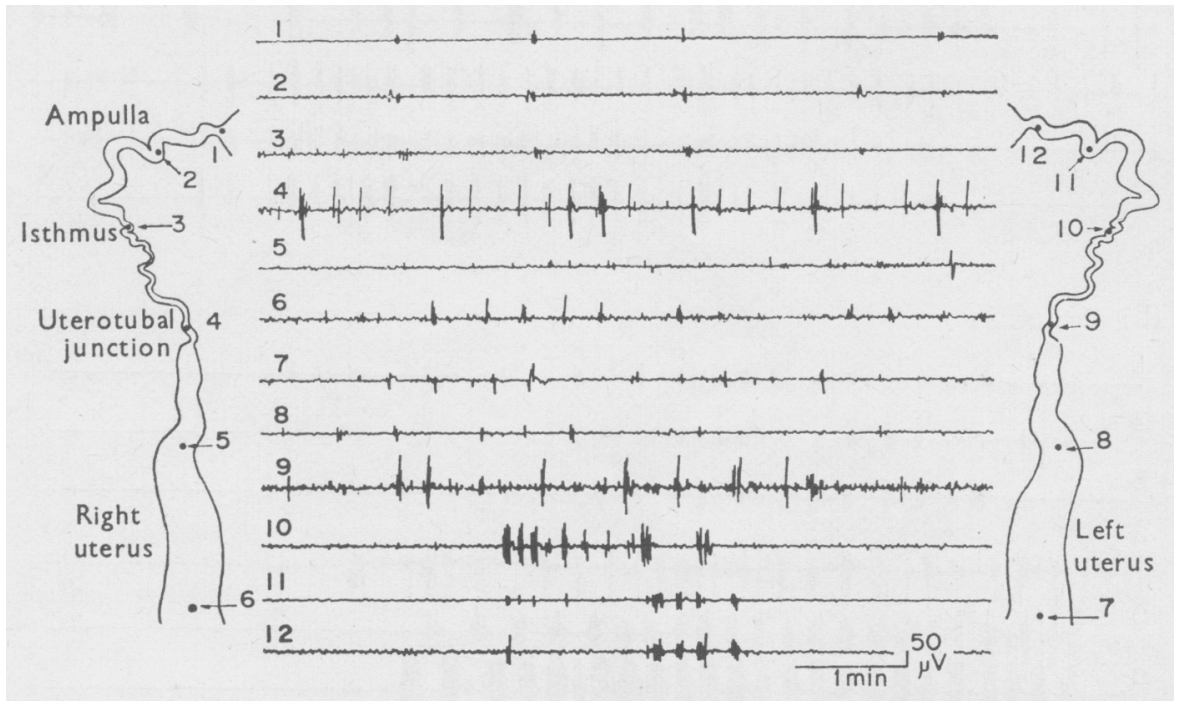

Text-fig. 1. The electrical activity of the oviduct and uterus of a ewe during dioestrus. Recordings were made 10 days after insertion of a progestagen-impregnated sponge. The recording sites are numbered 1 to 6 for the right oviduct and uterus in descending order, and 7 to 12 in ascending order for the opposite sites.

The onset of natural oestrus was indicated by an increase in the amplitude and frequency of the potentials within $24 \mathrm{hr}$ of the decrease in progesterone levels (Table 1). Potentials, grouped into bursts lasting 5-10 sec, were recorded initially on the oviduct. They recurred at 30 -min intervals, in phases lasting 5-6 min, and subsequently were also recorded on the uterus for 10-15 min periods. Withdrawal of the progestagen-impregnated sponge produced comparable changes, except that the development of bursts of activity took $36 \mathrm{hr}$, compared with $24 \mathrm{hr}$ for normal oestrus (Text-fig. 2a). The uterotubal activity became progressively more continuous, especially on the isthmus. This continuous period of uterotubal activity lasted about $12 \mathrm{hr}$ at natural oestrus and was again prolonged, to $24 \mathrm{hr}$, at the progestagen-induced oestrus.

Phases of activity then reappeared, lasting 5-6 $\mathrm{min}$ for the uterus and 2-3 min for the oviduct. Each phase consisted of 15-25 bursts of activity, approximately the same number as that recorded at the onset of oestrus, but condensed into a much shorter time (Text-fig. 2b). This pattern of activity was seen for $12 \mathrm{hr}$ at natural oestrus and for $24 \mathrm{hr}$ at the progestagen-induced oestrus. The end of oestrus was characterized by a progressive decrease in the amplitude of potentials and in the duration of bursts. 


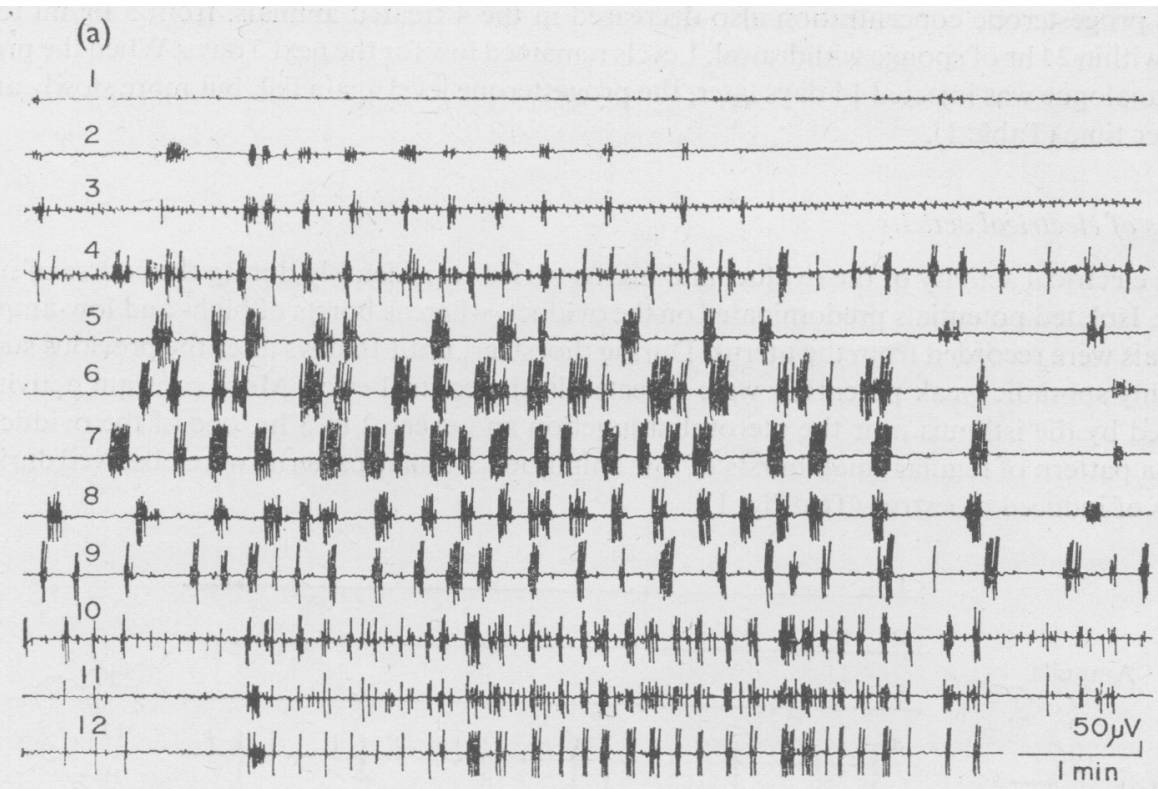

(b)

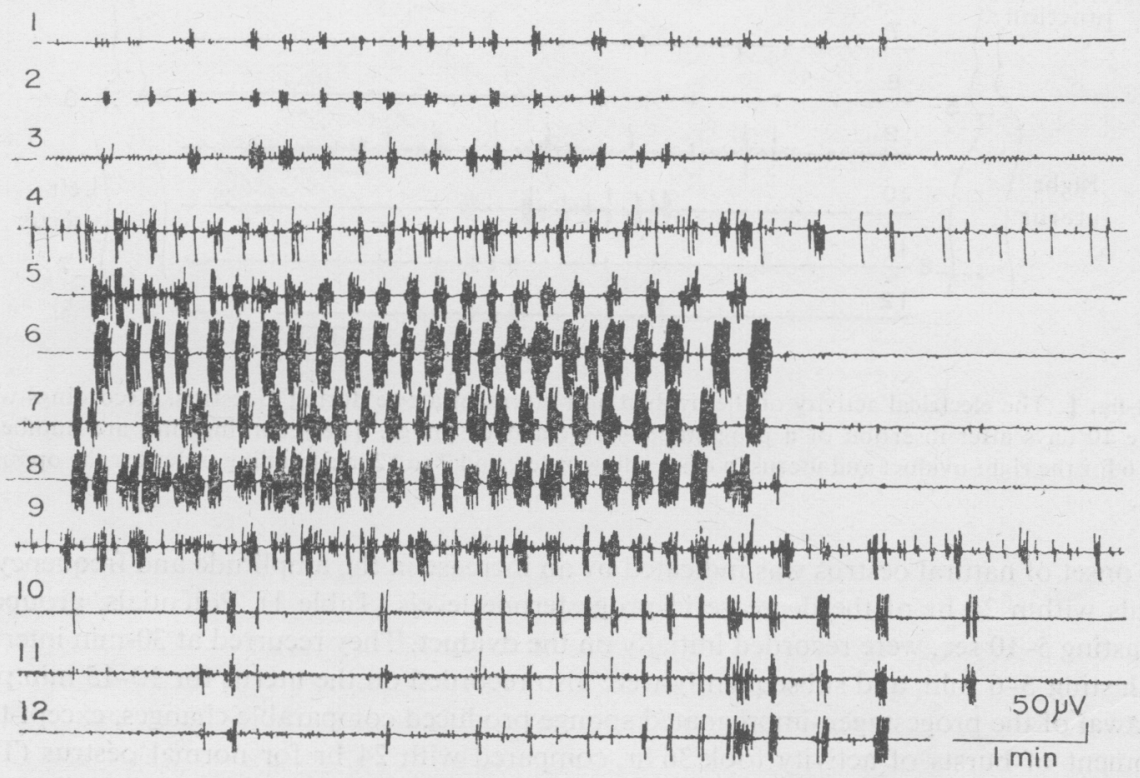

Text-fig. 2. Uterotubal activity during oestrus (a) 2 and (b) 3 days after withdrawal of a progestagenimpregnated sponge and injection of PMSG. The tracings are numbered as for Text-fig. 1. In (a) the series of bursts on the uterus lasts about $10 \mathrm{~min}$. Continuous spiking activity is seen on the isthmus (traces 3 and 10) with a period of superimposed bursts over the whole of one oviduct. In (b) the number of bursts on the uterus is similar to that in (a) but the bursts are condensed into a 5 -min period. Spiking activity on the uterotubal junction (traces 4 and 9 ) is increased.

Injection of the prostaglandin analogue and PMSG induced within $30 \mathrm{~min}$ an immediate stimulatory effect at all recording sites which lasted for 2-3 hr. A comparable sequence of events to those 
previously described then developed within $36 \mathrm{hr}$, and continued for $36 \mathrm{hr}$. Despite this faster progression of changes, the successive involvement of the oviduct and uterus was still clear. However, the intensity of the activity was less than at natural oestrus; the potentials of the oviduct were grouped into bursts lasting only $2-5 \mathrm{sec}$ and the phases of activity of the uterus consisted of only 7-10 bursts.

\section{Temporal organization of activity}

Several patterns of propagation of activity were observed on the uterus. At the onset of oestrus, series of ascending contractions predominated but these often appeared to be triggered by a descending contraction of the opposite horn. The ascending contractions frequently spread out through the uterotubal junction and involved the whole oviduct. Towards the end of oestrus synchronous descending contractions of both horns were numerous, some of them appearing to originate on the oviduct near the uterotubal junction.

Summation of the electrical activity of the uterus at $30-\mathrm{sec}$ intervals showed the progressive increase and subsequent decrease of activity, which took 48,72 and $36 \mathrm{hr}$ at natural oestrus, progestagen-induced oestrus (Text-fig. 3) and after prostaglandin treatment, respectively. At the onset of natural or progestagen-induced oestrus, the contractions of the uterine horns occurred independently and the daily number of contractions for one horn was as much as one-third higher than that of the other. The more active horn was associated with the more active oviduct. The contractions then synchronized before again becoming independent at the end of oestrus (Text-fig. 3). Tubal activity of natural and progestagen-induced oestrus also showed independent patterns of activity between the two sides in early and late oestrus, corresponding with the activities of the respective uterine horns. No such asymmetry in the uterotubal activity was observed after the injection of prostaglandin analogue and PMSG.

\section{Discussion}

The results of the present experiments show that maximal rhythmic uterine activity occurs at the peak of oestrus, whether natural or induced. The direction of propagation of the uterine contractile waves was frequently reversed, as reported by Naaktgeboren et al. (1973). A descending contraction starting on one of the oviducts followed by several ascending contractions on the opposite horn agrees with the report of Croker \& Shelton (1973) and the observations of Hawk (1975) who found that about $67 \%$ of the uterine contractions move anteriorly $5 \mathrm{hr}$ after the onset of oestrus while approximately equal numbers of ascending and descending contractions occurred on both horns during late oestrus. This change may be due to a decrease in the initiatory role of the oviduct coupled with a stronger uterine activity so that the direction of contractions is controlled by isthmic activity at the beginning of oestrus and by uterine body activity towards the end. Unilateral section of the uterotubal junction in the rabbit has provided evidence for such a control mechanism (Ruckebusch, 1975).

The observation that the isthmi differed in their responsiveness to adrenergic drugs, both in vitro (unpublished data) and in vivo (Ruckebusch \& Pichot, 1975), suggests a differential sensitivity of the oviducts. This asymmetry of tubal activity may be related to the presence of a corpus luteum on one ovary. A role for the corpus luteum is further supported by the disappearance of asymmetry of tubal activity after the rapid luteolysis produced by the prostaglandin treatment, this phenomenon being less marked in the case of the more gradual luteolysis at the end of a normal oestrous cycle.

Behavioural oestrus is reported to last for $51 \mathrm{hr}$ after progestagen synchronization (Tomkins \& Bryant, 1974). The phase of high intensity behaviour thus corresponds to the period of continuous electrical activity of the uterus. The number of bursts in each phase of activity which increased from approximately $1-3 / \mathrm{min}$ at the onset of oestrus to $3-4 / \mathrm{min}$ later correlates with the $25 \%$ increase in the rate of uterine uncoilings seen over the same period by Lehrer \& Schindler (1974). Variation in the strength of the bursts may explain the partial and incomplete uncoilings described by these authors. It is likely that similar changes occurred in natural oestrus in view of the comparable 


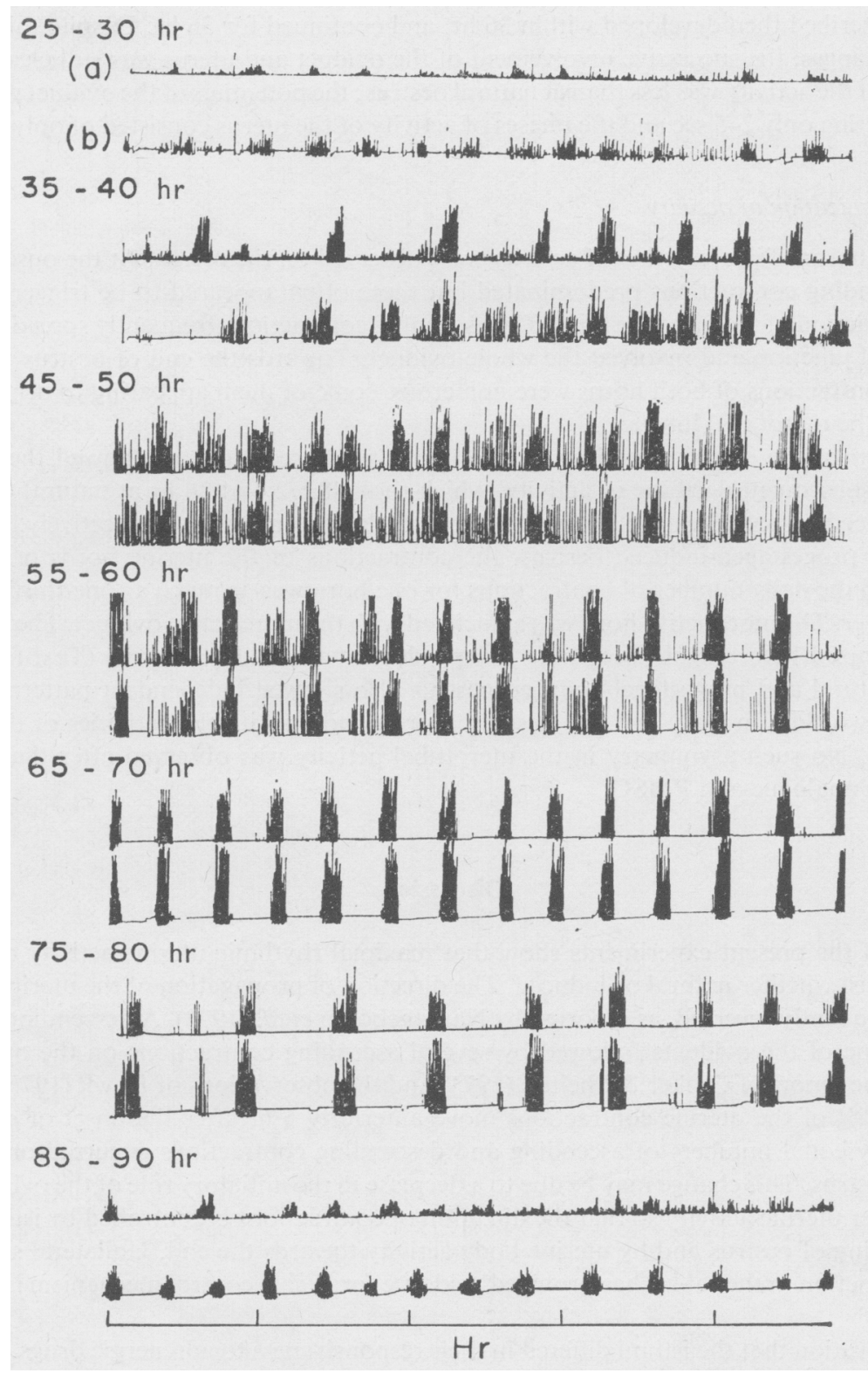

Text-fig. 3. Summation at $30-\mathrm{sec}$ intervals of the uterine activity in the ewe. Tracings of the right (a) and left (b) horns over 5-hr periods from 25 to $90 \mathrm{hr}$ after sponge withdrawal and PMSG injection. Full scale deflections on the ordinate correspond to $16 \mu \mathrm{C}$. Contractions in the two horns are not synchronous until the 55 th hr. After this time, quiescent periods became more marked resulting in definite periods of contractions as shown in Text-fig. 2(b).

patterns of electrical activity. With prostaglandin treatment, the relatively smaller magnitude and shorter duration of the activity may be associated with fewer uncoiling movements and possibly a reduction in behavioural receptivity, as seen by Hawk (1973).

The prolonged depression of progesterone level after sponge withdrawal was associated with an equally prolonged pattern of electrical activity. In contrast, prostaglandin injection was unable to reproduce either the intensity of electrical activity or the rapid decrease in progesterone levels ob- 
served in natural oestrus. Differences in the amount and timing of the prostaglandin injection may increase the effectiveness of this treatment. The use of PMSG or its replacement by oestrogen (Croker \& Shelton, 1973) should also be considered since a transient rise in oestrogen levels successively initiates the changes in uterine motility described (Hawk, 1975). These points may be of importance in order to obtain maximum fertility.

We thank Dr P. Lockwood of Imperial Chemical Industries for supplying ICI 80,996 and Dr F. Le Provost of Searle Laboratories for supplying progestagen (SC 9880) and PMSG. The technical assistance of Mrs G. Costes is acknowledged. The work was supported by a grant from I.N.R.A. (Veterinary Research).

\section{References}

Croker, K.P. \& Shelton, J.W. (1973) Influence of stage of cycle, prostaglandin treatment and dose of oestrogen on uterine motility in the ewe. J. Reprod. Fert. 32, 521-524.

Haresign, W., Foster, J.P., Haynes, N.B., Crighton, D.B. \& LAMmING, G.E. (1975) Progesterone levels following treatment of seasonally anoestrous ewes with synthetic LH-releasing hormone. $J$. Reprod. Fert. 43, 269-279.

HAWK, H.W. (1973) Uterine motility and sperm transport in the estrous ewe after prostaglandin induced regression of corpora lutea. J. Anim. Sci. 37, 13801385.

HAWK, H.W. (1975) Hormonal control of changes in the direction of uterine contractions in the estrous ewe. Biol. Reprod. 12, 423-430.

LATour, A. (1973) Un dispositif simple d'analyse quantitative de l'électromyogramme intestinal chronique. Annls Rech, vétér. 4, 347-353.

Lehrer, A.R. \& SCHINDLER, H. (1974) Uterine motility of the ewe during the estrous cycle. J. Anim. Sci. 28, 86-88.

LightFoot, R.J. (1970) The contractile activity of the genital tract of the ewe in response to oxytocin and mating. J. Reprod. Fert. 21, 376.

NAAKTGEBoren, C., VAN DER Weyden, G.C., KLOPPER, P.J., Kroon, C.H., Schoof, A.G. \& TAVERne, M.A.M. (1973) Electrophysiological observations of uterine motility during the oestrous cycle in sheep. $J$. Reprod. Fert. 35, 511-518.

Rousseau, J.P. \& Prud'homme, M.J. (1974) Etude électromyographique de la motricité de l'utérus chez la brebis. Action des hormones. Annls. Biol. anim. Biochim. Biophys. 14, 67-85.

RuCKebusch, Y. (1975) Relationship between the electrical activity of the oviduct and uterus of the rabbit in vivo. J. Reprod. Fert. 45, 73-82.

RuCKebusCH, Y. \& BAYARD, F. (1975) Motility of the oviduct and uterus of the cow during the oestrous cycle. J. Reprod. Fert. 43, 23-32.

RuckebusCh, Y. \& Pichot, D. (1975) Effects of adrenergic drugs on sheep oviduct motility. Eur. $J$. Pharmac. 33, 193-196.

TOMKINS, T. \& BRYANT, M.J. (1974) Oestrous behaviour of the ewe and the influence of treatment with progestagen. J. Reprod. Fert. 41, 121-132.

Received 17 October 1975 